\title{
Molecular Phylogeny of Silk Producing Insects Based on Internal Transcribed Spacer DNA1
}

\author{
Botlagunta Mahendran, Sudip K. Ghosh and Subhas C. Kundu* \\ Department of Biotechnology, Indian Institute of Technology, Kharagpur 7213 02, India
}

Received 7 February 2006, Accepted 27 April 2006

Silk moths are the best studied silk secreting insects and belong to the families Bombycidae and Saturniidae. The phylogenetic relationship between eleven silk producing insects was analyzed using the complete DNA sequence of the internal transcribed spacer DNA 1 locus. The PCR amplification and sequence analysis showed variation in length ranging from 138 bp (Antheraea polyphemus) to 911 bp (Hyalopora cecropia). Microsatellite sequences were found and was be used to distinguish Saturniidae and Bombycidae members. The nucleotide sequences were aligned manually and used for construction of phylogenetic trees based on Maximum parsimony and Maximum likelihood methods. The topology in both the approaches yielded a similar tree that supports the ancestral position of the Antheraea assama.

Keywords: Internal transcribed spacer DNA 1, Phylogeny, Silkworms

\section{Introduction}

Economically important silk producing insects of order Lepidoptera have been classified into two major groups viz mulberry and non-mulberry. Mulberry silk is mainly produced by the domesticated species Bombyx mori, originated from $B$. mandarina (wild counterpart) by gene duplication and chromosomal fusion mechanism (Hwang et al., 1999a and b; Banno et al., 2004). The non-mulberry silks are different types viz., tropical tasar (Antheraea mylitta), oak tasar (A. frithi, A. pernyi, A. roylei and A. proylei), muga (A. assama), eri (Philosamia ricini) and fagaria (Attacus atlas) are mainly produced by Saturniidae family and Shashe by Gonometa postica of Lasiocampidae family. They all show variations in

\footnotetext{
*To whom correspondence should be addressed.

Tel: 91-3222- 283764; Fax: 91-3222-278433

E-mail:kundu@hijli.iitkgp.ernet.in
}

their phenotypic traits such as cocoon color and weight, silk ratio and host plant preference. The silks produced by these insects are generally cultivated in India, China, Japan, Indonesia and Thailand for commercial purpose. Among which the Indian tropical tasar A. mylitta cocoons have the highest capacity of silk production being the largest among all the other known non-mulberry silk producing insects (Akai, 2000). Though they have a great commercial value these species are mainly classified on the basis of morphological attributes such as follicular imprints on the chorine egg, the arrangement of tubercular setae on the larvae and karyotyping data (Jolly et al., 1985; Sinha et al., 1994). The classification of the species on the basis of phenotypic attributes is sometimes erratic and misleading. However, a number of molecular markers like random amplified polymorphic DNA (RAPD), restriction fragment length polymorphism (RFLP), simple sequence repeat (SSR), fluorescent dye labeled ISSR PCR reaction (FISSR-PCR) and single nucleotide polymorphism (SNP) analysis have been developed to distinguish the genetic diversity among silkworm species (Yasukochi, 1998; Reddy et al., 1999b; Tan et al., 2001; Nagaraju et al., 2002; Cheng et al., 2004; Mahendran et al., 2005; Mahendran et al., 2006). Majority of those studies focused mainly on the genetic diversity between different B. mori strains. However, Hwang et al. (1999) developed a mitochondrial sequence based marker to distinguish $B$. mori and B. mandarina of Bombycidae family and $A$. pernyi and A. yamamai of Saturnidae family members (Shimada et al., 1995; Prasad et al., 2005; Li et al., 2005). Therefore, it is imperative to develop a molecular marker system to study the genetic background of more number of economically important non-mulberry silk species.

The nuclear ribosomal DNA is arranged in tandemly repeated clusters, where transcription units alternate with nontranscribed units called spacers (Long and David, 1980), representing a multigene family located on one or more chromosomes (Avise, 1994). The internal transcribed spacer DNA1 (ITS1) region and internal transcribed spacer DNA2 (ITS2) are flanked by highly conserved sequences, the $18 \mathrm{~S}$, $5.8 \mathrm{~S}$ and $28 \mathrm{~S}$ nuclear ribosomal DNA genes. These regions 
do not undergo any selection pressure, which leads to high variability in the spacer regions. For this reason ITS1 and ITS2 have been employed to resolve phylogenetic problems in lower taxonomic level such as species or populations (Van Herwerden et al., 1999; Haris and Crandall, 2000; Marcilla et al., 2001; Marquez et al., 2003). It has been used in plants (Coleman, 2002), bilaterians like nematodes, insects and crustaceans (Chu et al., 1997; Hugall et al., 1999; Therriault et al., 2004), as well as in basal metazoans such as corals (Vidigal et al., 2004) and sponges (Duran et al., 2003) for phylogenetic analyses.

In this report we have used the ITS1 sequence to study the genetic variability between more numbers of silk producing insects.

\section{Materials and Methods}

Collection of different silkworm species. The live cocoons of $A$. mylitta (DQ164778), A. frithi (DQ164779), A. assama (DQ164783), A. pernyi (DQ164780), A. roylei (DQ164780), A. proylei (DQ164782), A. polyphemus (DQ164782), P. ricini (DQ164784), H. cecropia (DQ164787), G. postica (DQ164786) and B. mori (DQ164788) were collected from different locations in India and other countries. The DNA sequence of $A$. atlas and B. mandarina was obtained from NCBI data base (AF463459 and AF395878) to study the sequence evolution of ITS 1 and for the phylogenetic analysis. The geographical distribution, host plant and type of the silk produced by the particular species are presented in Table 1 .
Genomic DNA isolation. Genomic DNAs from different silkworm's species were isolated from either fresh or frozen single individual pupa by the laboratory protocol as mentioned by Datta et al. (2001). Prior to DNA extraction, the digestive tract was removed from the pupal body by dissection. One gram of fat body tissue was ground in liquid nitrogen and incubated overnight at $50^{\circ} \mathrm{C}$ in the presence of $10 \mathrm{ml}$ digestion buffer $(0.01 \mathrm{M} \mathrm{NaCl}, 0.1 \mathrm{M}$ Tris $\mathrm{HCl}, 0.25 \mathrm{M}$ EDTA and $500 \mu \mathrm{l}(0.5 \%$ of $10 \%$ SDS $)$ with $100 \mu \mathrm{g} / \mathrm{ml}$ Protenase $\mathrm{K}$. Proteinase $\mathrm{K}$ digested samples were extracted twice with an equal volume of Tris-Cl saturated phenol $(\mathrm{pH}$ 8.0) followed by centrifugation at $5,000 \mathrm{~g}$ for 15 minutes to remove protein contaminants and debris. The supernatant was treated with RNAase at $37^{\circ} \mathrm{C}$ for $30 \mathrm{~min}$ followed by chloroform extraction and centrifugation at $5,000 \mathrm{~g}$ for 15 minutes. Finally, the aqueous phase from each separate tube was transferred separately to clean centrifuge tubes and mixed with 0.1 volumes of $3 \mathrm{M}$-sodium acetate ( $\mathrm{pH}$ 5.2). The genomic DNA was precipitated using 2 volumes of cold ethanol, washed twice with $70 \%$ ethanol, dried and suspended in $10 \mathrm{mM}$ Tris- $\mathrm{Cl}$ (pH 8.0).

Sequencing and analysis of nuclear ribosomal DNA. The primers were designed to amplify the full length internal transcribed spacer DNA1 (ITS1) and adjoining 5' or 3' end of the ribosomal DNA based on the published sequence of Attacus ricini (Acc. No AF463459). The primers used for the amplification of ITS1 were forward 5' GCGTTCGAAGTGTCGATG 3' and reverse 5' GTAGC GACGGGCGGTGT 3'. The PCR was carried out in $50 \mu \mathrm{l}$ using $1 \mathrm{U}$ of Taq polymerase (Roche) in thermal cycler (Perkin Elmer 2400). The PCR reaction conditions for ITS 1 was $94^{\circ} \mathrm{C}$ for $30 \mathrm{sec}$ (denaturation), $56^{\circ} \mathrm{C}$ for $1 \mathrm{~min}$ (annealing) and $72^{\circ} \mathrm{C}$ for $1 \mathrm{~min}$ for

Table 1. The different silk producing insects collected for this study

\begin{tabular}{|c|c|c|c|c|}
\hline Sl. No. & Species & Country & Type of silk & Host plants \\
\hline 1 & Antheraea mylitta & Central India & Tasar & $\begin{array}{l}\text { 1) Terminalia arjuna } \\
\text { 2) Terminalia tomentosa } \\
\text { 3) Shorea robusta }\end{array}$ \\
\hline 2 & Antheraea frithi & North East India & Oak & $\begin{array}{l}\text { 1) Lithocarpus dealbata } \\
\text { (Quercus dealbata) }\end{array}$ \\
\hline 3 & Antheraea assama & Eastern India & Muga & M. bombycina \\
\hline 4 & Antheraea pernyi & China & Oak & Quercus spp \\
\hline 5 & Antheraea roylei & North East India & Oak & Quercus spp \\
\hline 6 & Antheraea proylei & North East India & Oak & $\begin{array}{l}\text { 1) Quercus serrata } \\
\text { 2) Quercus incana }\end{array}$ \\
\hline 7 & Antheraea polyphemus & USA or Canada & - & $\begin{array}{l}\text { 1) Quercus alba } \\
\text { 2) Quercus nigra } \\
\text { 3) Quercus rubra }\end{array}$ \\
\hline 8 & Philosamia ricini & India & Eri & $\begin{array}{l}\text { 1) Ricinus communis } \\
\text { 2) M. utilissima }\end{array}$ \\
\hline 9 & Attacus atlas & Indonesia & Fagaria & $\begin{array}{l}\text { 1) Ailantus altissima } \\
\text { 2) Ligustrum, } \\
\text { 3) Syringa }\end{array}$ \\
\hline 10 & Hyalopora cecropia & USA or Canada & - & $\begin{array}{l}\text { 1) Acer saccharinum } \\
\text { 2) Prunus spp } \\
\text { 2) Quercus spp }\end{array}$ \\
\hline 11 & Gonometa postica & Namibia & Shashe & Colophospermum mopane \\
\hline 12 & $\begin{array}{l}\text { Bombyx mori } \\
\text { (Nistari strain) }\end{array}$ & Eastern India & Mulberry & $\begin{array}{l}\text { 1) Morus alba } \\
\text { 2) M. indica }\end{array}$ \\
\hline
\end{tabular}


35 cycles. The PCR products were gel purified using Qiagen gel extraction kit (Qiagen, Hilden, Germany). The purified DNA fragments were cloned into a pCR 2.1 TOPO TA cloning vector (Invitrogen, USA). The ligated products were transformed in DH5a strain of E. coli. The plasmids were isolated; the inserts were verified according to Sambrook and Russell (2001) and sequenced using automated cycle sequencing facility (ABI Prism 3770). The sequencing was performed using $400 \mathrm{ng}$ of plasmid DNA as a template and 2.0 pico moles of primer (M13 forward or reverse). The Sequencher (Gene Codes Corp) was used for sequence assembly and evaluation. The BLAST search engine (Altschul et al., 1997) was used to determine homologues sequence of ITS1 using 5.8S rRNA, 18S rRNA. The sequences were aligned using Clustal W (Thompson et al., 1994). The sequence statistics were obtained with MEGA 3.1 (Kumar et al., 2004). The sequences of ITS1 have been submitted to GenBank. BioEdit software was used to align 5.8S-ITS1-18S complex, with subsequent manual adjustment. We estimated secondary structures for the rRNA fragment containing ITS1 sequences with Mfold (Zuker, 2003) using folding temperature $\left(37^{\circ} \mathrm{C}\right)$, percent sub optimality $(5 \%)$, upper bound of computed foldings (50), window parameter (15), and maximum distance between paired bases as fixed parameters.

Phylogenetic analysis. The phylogenetic analyses were performed with PAUP*4.01 version beta 10 (Swofford, 2003) using Maximum Parsimony (MP) and Maximum Likelihood (ML) approaches. MP trees were produced using heuristic searches with 50 repetitions using random stepwise addition of taxa and gaps were also treated as missing characters, Tree-bisection-reconnection (TBR) branch swapping, Multrees option, and Accelerated transformation (ACCTRAN) character-state optimizations were in effect. Multiple state taxa were interpreted as uncertain and the branches were collapsed if the maximum length was zero. For all analyses, tree length (L), consistency indices, CI (Kluge and Farris, 1969), and retention indices, RI, (Farris, 1989) were reported. The internal stability of the inferred MP tree was measured by bootstrapping using 1000 replications (Felsenstein, 1985). Drosophila triauraria species was considered as an out-group.

The most appropriate substitution model for ML analysis was determined by using Modeltest, Version 3.06 (Posada and Crandall, 1998). The sequence divergence values were also calculated from the selected model. Rate of heterogeneity was expressed using gamma distribution with shape parameter.

\section{Results}

Sequence analysis of internal transcribed spacer DNA 1. Segment of internal transcribed spacer DNA 1 (ITS1) was PCR amplified from genomic DNA of different silkworm species using 5.8S and $18 \mathrm{~S}$ ribosomal DNA sequence specific primers. The amplified product obtained from different silkworm species showed variation in lengths (Fig. 1). Each amplified product was gel purified using Qiaquick gel extraction kit (Qiagen) and cloned in pCR2.1 TOPO TA cloning vector (Invitrogen). Both the strands of each segment were sequenced by dye terminator method using automated

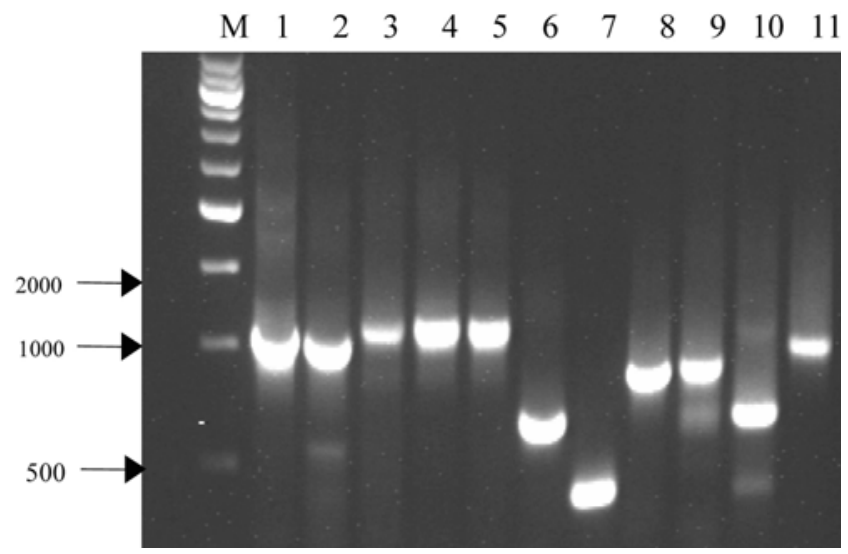

Fig. 1. PCR amplified profile of internal transcribed spacer DNA1 (ITS1) between silk producing insects, and are separated on $1 \%$ agarose gel electrophoresis. Lanes showing 1: A. mylitta, 2: A. frithi, 3: A. pernyi, 4: A. roylei, 5: A. proylei, 6: A. assama, 7: A. polyphemus, 8: P. ricini, 9: A. atlas, 10: G. postica and 11: B. mori respectively. $M$ represents molecular weight standard (XVII, $500 \mathrm{bp}$ ladder, Roche) and the numbers indicate base pairs.

DNA sequencer ABI 3700. The 5.8S rDNA-ITS1-18S rDNA ranges from 424 to $1,197 \mathrm{bp}$ between silkworm species including $114 \mathrm{bp}$ of $5.8 \mathrm{~S}$ rRNA, ITS1 and $172 \mathrm{bp}$ of $18 \mathrm{~S}$ rRNA. Among the silk producing insects analyzed, $A$. polyphemus and $H$. cecropia were found to have the shortest and longest ITS1 (138 and 911 bp respectively). We have developed RFLP and satellite DNA based markers to discriminate the intra genetic diversity of $A$. mylitta (Mahendran et al., 2005: Mahendran et al., 2006). The ecoraces of $A$. mylitta showed substantial variation in RFLP pattern and DNA sequence of satellite DNA. An attempt has been made to understand the intragenetic diversity of ITS 1 locus within nine different commercially utilized ecoraces of A. mylitta. Due to very short ITS1, A. polyphemus sequence was not considered for phylogenetic analysis. The BLAST analysis of the ITS1 sequence showed homology with Attacus ricini of Saturniidae family member. The sequences were aligned using the multiple sequence alignment algorithms in the programme Clustal W 1.7 (Thompson et al., 1994) and then adjusted manually to determine the genetic relationship among silk species. B. mandarina sequence was obtained from NCBI database (Acc. No. AF395878) for sequence comparison and phylogenetic analysis. ITS1 sequence alignment (including the gaps) was 1924 sites including 882 variable sites, of which 496 were parsimony informative was calculated using MEGA software. Multiple insertions and deletions, as well as numerous point substitutions, are revealed. The average nucleotide percentage for ITS1 is $\mathrm{A}=25.6 ; \mathrm{T}=$ 22.0; $\mathrm{C}=27.7$; and $\mathrm{G}=24.7$. The ITS1 sequences of Bombycidae members showed high AT content whereas in Saturniidae family members GC content was more than $50 \%$ (52.2-56.9\%, Table 2). Multiple sequence alignment among Saturniidae members revealed a consensus 33 bp (CGCTCGT 
Table 2. Accession number, size in base pairs, GC compositions of internal transcribed spacer DNA 1 (ITS1) sequences of different silkworm species

\begin{tabular}{lcc}
\hline Silkworm and accession number & Size (bp) & GC (\%) \\
\hline A. mylitta (DQ164778) & 780 & 55.4 \\
A. frithi (DQ164779) & 744 & 55.0 \\
A. pernyi (DQ164781) & 870 & 56.6 \\
A. roylei (DQ164780) & 864 & 56.9 \\
A. proylei (DQ164782) & 870 & 56.9 \\
A. assama (DQ164783) & 412 & 52.7 \\
A. polyphemus (DQ164785) & 138 & 36.2 \\
P. ricini (DQ164784) & 627 & 55.6 \\
A. atlas (AF463459) & 629 & 55.5 \\
H. cecropia (DQ164787) & 911 & 52.3 \\
G. postica (DQ164786) & 414 & 42.6 \\
B. mori (DQ164788) & 772 & 39.9 \\
B. mandarina (AF395878) & 768 & 39.4 \\
\hline
\end{tabular}

GGTACGGATTYYCACCAGTCKRMGCG) motif with 84\% sequence identity with each other. Short simple sequence repeats (microsatellites); $(\mathrm{CA})_{2-16,}(\mathrm{TA})_{5,}(\mathrm{CGA})_{3}$ and $(\mathrm{A} \text { and } \mathrm{T})_{2-9}$ were identified in ITS1 sequence of $B$. mori and they were unique to Bombycidae members. No such repeats were identified in either Saturniidae or Lasiocampidae members.

Secondary structure of ITS I between silkworm species. The predicted ITS1 secondary structure of A. mylitta, A. frithi, A. pernyi, A. roylei, A. proylei and H. cecropia displayed a similar structure imperfect hairpin with variation in folding at distal end structure whereas the other members of Saturniidae family such as $A$. assama, $A$. polyphemus and $P$. ricini had unique secondary structure. Most of the species of genus Antheraea represented the most energy efficient shape for each species ( $\Delta \mathrm{G}$ values of $-328.26,-278.68,-371.43,-363.26$ -382.2 and -128.58 for A. mylitta, A. frithi, A. pernyi, A. roylei, $A$. proylei and $A$. assama respectively), where as $A$. polyphemus (only a single species of genus Antheraea available in the Nearctic region, USA) was having a highest $\ddot{A G}$ value -25.22. The flanking regions of the ITS, 5.8S and $18 \mathrm{~S}$ rRNA were not considered for structure prediction, it has been considered that the folding of 5.8S and 18S rRNA was independent from that of ITS1 (Gutell, 1993). Secondary structure of $A$. polyphemus was completely different from the other members in the same genus. The Indian domesticated Saturniidae family member $P$. ricini shared a conserved secondary structure ( $\Delta \mathrm{G}-222.26)$ with the Indonesian wild species Attacus atlas ( $\Delta \mathrm{G}-222.26)$. G. postica, the only a member of Lasiocampidae family had unique secondary structure. Secondary structure of Bombycidae family members had a distinct secondary structures were completely different from Saturniidae members. This uniqueness may be attributed due to the presence of a stretch of microsatellites in Bombycidae members (Fig. 2).
Phylogenetic analysis. A heuristic parsimony analysis of the fourteen silk producing insects was carried out using PAUP*4.01 (Swofford, 2003). Maximum parsimony (MP) analysis yielded a single tree with a length of $1335, \mathrm{CI}=$ 0.898 and $\mathrm{RI}=0.853$ respectively (Fig. 3a) using Drosophila triauraria as an out-group. This tree forms two major groups 1) all non-mulberry silkworms (Saturniidae and Lasiocampidae families) in one group and 2) mulberry silkworms (Bombycidae family) are in another group. Within Saturniidae, the species of two different tribes Antheraea (A. mylitta and A. frithi, A. pernyi, A. roylei, A. proylei, A. polyphemus and A. assama) and Attacini (Philosamia ricini, Attacus atlas and Hyalopora cecropia) members made two distinct clades with significant bootstrap value. Within Antheraea species A. proylei, A. pernyi and $A$. roylei shared a single group and occupied the crown of the tree. A. mylitta made a distinct clade with its neighboring oak silk producing insect $A$. frithi followed by muga silkworm A. assama. A. assama occupied base of the Antheraea members and was close to $P$. ricini. The $P$. ricini clustered with the largest silkmoth, A. atlas followed by $H$. cecropia. Gonometa postica, the only member of Lasiocampidae family clade with Saturniidae members.

For Maximum Likelihood (ML) analysis the appropriate model, $\mathrm{HKY}+\mathrm{G}$ was selected using Modeltest. In this model, the base frequencies were unequal 0.3012 (A), 0.2401 (C), $0.2114(\mathrm{G})$ and $0.2473(\mathrm{~T})$. The estimated shape parameter for the gamma distribution was $\alpha=5.2821$. The estimated transition and transversion ratio was 0.5616 . Incorporating $\mathrm{HKY}+\mathrm{G}$ model of molecular evolution, the phylogenetic relationship among taxa was estimated. A single ML tree was recovered $(-\ln L=7161.5215)$ (Fig. 3b). Besides the small differences in the bootstrap values and the relative position of A. pernyi, A. roylei and A. proylei, the ML tree was almost similar to MP tree.

\section{Discussion}

The evolution of economically important silk producing insects is described for the first time based on internal transcribed spacer DNA1 (ITS1). The PCR amplification and gel electrophoresis pattern revealed size variations of ITS1 among the species. Size of PCR amplified products of morphological related species of Saturniidae family members found to be similar. This partly explains the observed length variation of ITS1 in gel electrophoresis in contrast to mitochondrial genes include large ribosomal subunit (16S rRNA) and Cytochrome oxidase genes (Hwang et al., 1999 a and b). The sequence comparisons of ITS1 between species suggest substantial differences among them and these variations may accumulated due to unequal crossing over, replication slippage or rates of recombination after the split of the two species that occurred long ago (Smith, 1976; Strand et al., 1993; Viguera et al., 2001). For example A. proylei, a hybrid between A. pernyi ( $2 \mathrm{n}$ $=98)$ of China and A. roylei $(2 \mathrm{n}=60)$ of the Himalayan belt 

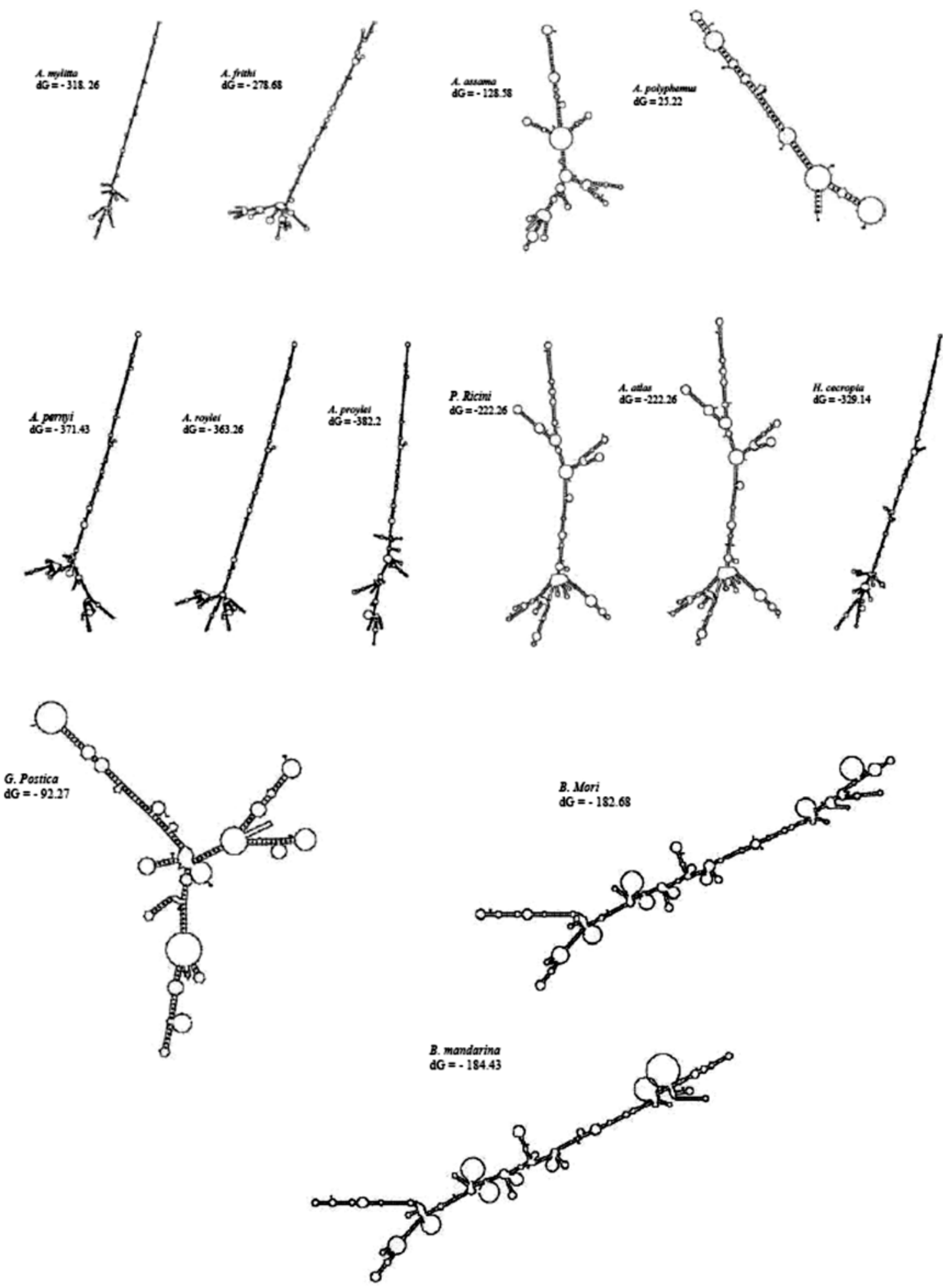

Fig. 2. Predicted secondary structure of internal transcribed spacer 1 for the silkworm species of Saturniidae, Bombycidae and Lasiocampidae family members.

of India (Nagaraju and Jolly, 1985; Bhagirath et al., 1988; Kundu et al., 1991). It showed sequence divergence in nine alignment positions in contrast to pernyi and roylei, comprising four transversions (nos: 288, 291, 374, 375) one transitional change (nos. 360), two insertions (nos. 377, 872-874) and one deletion (no.842) resulted in inconsistent folding at distal ends in their secondary structure with respect to A. pernyi and $A$. roylei. The sequence analysis of $P$. ricini (domesticated 


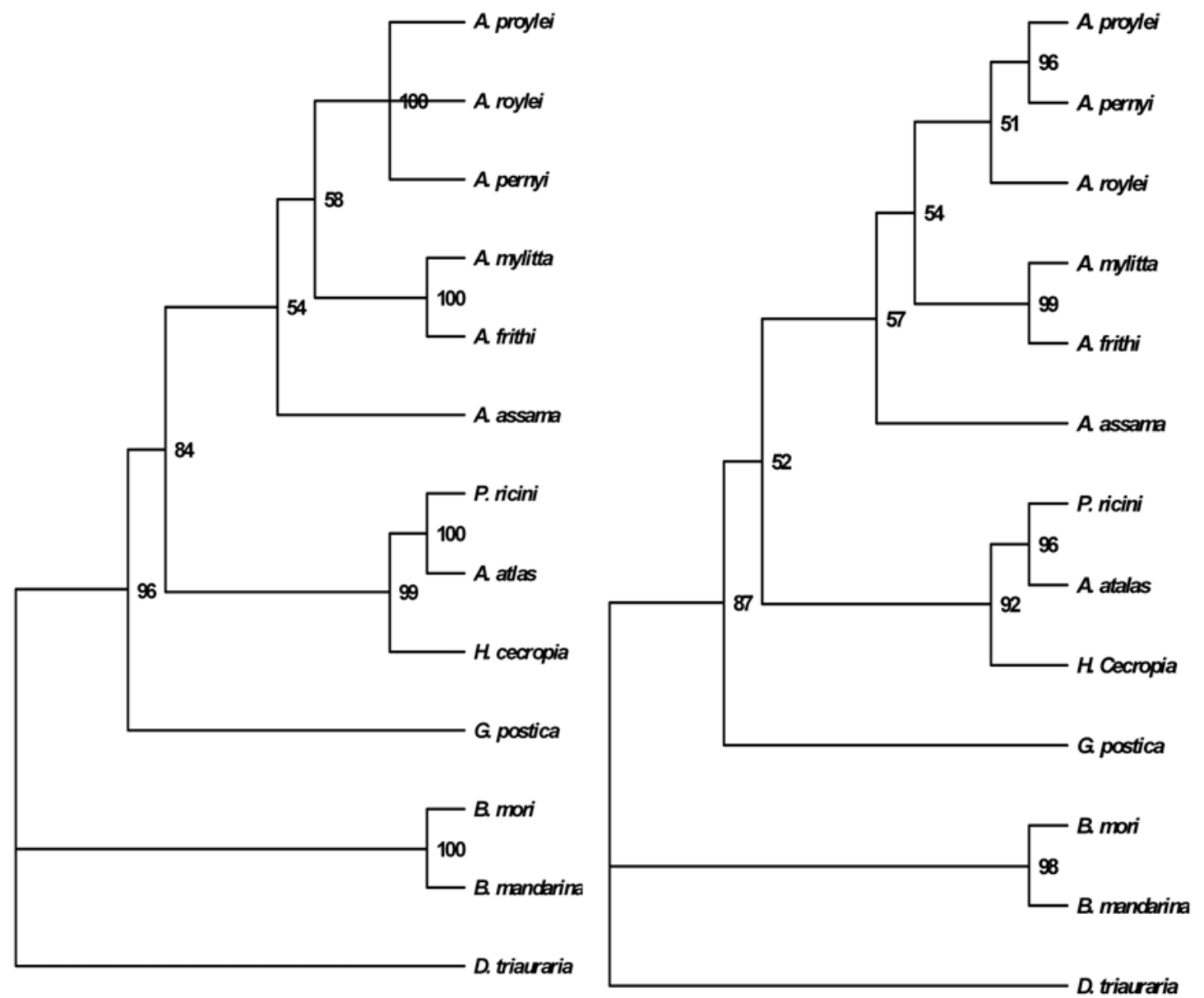

Fig. 3. Comparative analysis of (A) Maximum Parsimony (MP) and (B) Maximum Likelihood (ML) trees. Estimated parameters for parsimony analysis are consistency index (CI) of 0.898 and retention index (RI) of 0.853 . The tree was rooted using D. triauraria as an out-group. Numbers inside the branches are bootstrap values for 1000 replications. The bootstrap analysis using maximum parsimony showed slightly higher confidence values than Maximum likelihood algorithm, but it could not able to resolve the node point between A. proylei, A. pernyi and A. roylei. However Maximum likelihood tree clearly resolved the node point between the hybrids (A. proylei) in contrast to their parents (A. pernyi x A. roylei).

species in Saturniidae family) shows almost identical to $A$. atlas (wild species). The Bombycidae members display a stretch of microsatellite and a high AT bias $(60.5 \%$ in $B$. mandarina; $60.1 \%$ in $B$. mori) in comparison to Saturniidae members. On the other hand concerted evolution might be played a major role in sequence homogenization of ITS 1 at intra population level. (Dover, 1982).

The phylogenetic relationship between different silk producing species is established on the basis of nuclear ribosomal repeat unit using Maximum parsimony (MP) and Maximum likelihood (ML) methods. Drosophila triauraria is used as an out group. Despite the differences in bootstrap values and the relative position the tree topology support the morphological, cytological (Jolly, 1985), mitochondrial (Hwang et al., $1999 \mathrm{a}$ and b) and microsatellite DNA based tree phylogeny (Prasad et al., 2005). A. proylei occupies crown of the tree and A. assama occupies the base of the tree. A controversy arose during the 1970 `s, since one group of taxonomists assigned the hybrid status (A. pernyi x A. roylei) as species, calling it $A$. proylei where as the other group considered it just a hybrid. Based on sequence and structure divergence of ITS1 our data support the recently derived species of $A$. proylei. The ITS1 tree topology also supports sister group relationship between Antheraea and Attacini tribes within the Saturniidae family. G. postica, a member of Lasiocampidae family superflock with the Saturniidae family members. The Saturniidae members made a separate group with Bombycidae family members (B. mori and B. mandarina).

From this study it is reasonable to think that variation of ITS1 sequences can be starting reference for the identification of genetic marker for phylogenetic studies to differentiate species. 
Acknowledgments Labanyamayee Das Molecular Genetics Laboratory and Bioinformatics facilities have been used for this work. The financial supports were obtained from DBT, CSIR and MHRD, New Delhi and B. M. received individual Senior Research Fellowship from the CSIR. We wish to thank Central Tasar Research and Training Institute, Ranchi, Mr. P. Mukherjee (Midnapur), Mr. Bill Oehlke (Canada), Mr. S. Dey (Orissa), Dr. Ibohal Singh, Dr. N. Ibotombi (Imphal, Manipur) and Mr. Ian Cummings (Namibia) for providing the silkworm samples.

\section{References}

Akai, H. (2000) Cocoon filament characters and post-cocoon technology. International Journal of Wild Silkmoths and Silk. 5, 255-259.

Altschul, S. F., Madden, T. L., Schaffer, A. A., Zhang, J., Zhang, Z., Miller, W. and Lipman, D. J. (1997) Gapped BLAST and PSI-BLAST: a new generation of protein database search programs. Nucleic Acids Res. 25, 3389-3402.

Avise, J. C. (1994) Molecular Markers, Natural History, and Evolution, Chapman \& Hall, New York, USA.

Banno, Y., Nakamura, T., Nagashima, E., Fujii, H. and Doira, H. (2004) M chromosome of the wild silkworm, Bombyx mandarina $(\mathrm{n}=27)$, corresponds to two chromosomes in the domesticated silkworm, Bombyx mori $(\mathrm{n}=28)$. Genome 47, 96-101.

Bhagirath, T. H., Kundu, S. C. and Ibotombi, N. (1988) Ultimate karyotype of the hybrid between Antheraea pernyi and $A$. roylei. Sericologica. 28, 91-94.

Cheng, T. C., Xia, Q. Y., Qian, J. F., Liu, C., Lin, Y., Zha, X. F. and Xiang, Z. H. (2004) Mining single nucleotide polymorphisms from EST data of silkworm, Bombyx mori, inbred strain Dazao. Insect Biochem. Mol. Biol. 34, 523-530.

Chu, K. H., Tam, P. F., Fung, C. H. and Chen, Q. C. (1997) A biological survey of ballast water in container ships entering Hong Kong. Hydrobiologia. 352, 201-206.

Coleman, A. W. and Vacquier, V. D. (2002) Exploring the phylogenetic utility of ITS sequences for animals: a test case for abalone (Haliotis). J. Mol. Evol. 54, 246-257.

Datta, A., Ghosh, A. K. and Kundu, S. C. (2001) Differential expression of fibroin gene in developmental stages of silkworm A. mylitta (Saturniidae). Comparative Biochemistry and Physiology Part B. 129, 197-204.

Dover, G. A. (1982) Molecular drive: a cohesive mode of species evolution. Nature 295, 111-117.

Duran, A. L., Yang, J., Wang, L. and Sumner, L. W. (2003) Metabolomics spectral formatting, alignment and conversion tools (MSFACTs). Bioinformatics 19, 2283-2293.

Farris, J. S. (1989) The retention index and homoplasy excess. Systematic Zool. 38, 406-407.

Felsenstein, J. (1985) Congruence limits on phylogenies: An approach using the bootstrap. Evolution. 39, 783-791.

Gutell, R. R., Larson, N. and Woese, C. R. (1994) Lessons from an evolving rRNA: $16 \mathrm{~S}$ and $23 \mathrm{~S}$ rRNA structures from a comparative perspective. Microbio. Rev. 58, 10-26

Haris, D. J. and Crandall, K. A. (2000) Intragenomic variation within ITS1 and ITS2 of freshwater crayfishes (Decapoda: Cambaridae): implications for phylogenetic and microsatel- lite studies. Mol. Biol. Evol. 17, 284-291

Hugall, A., Stanton, J. and Moritz, C. (1999) Reticulate evolution and the origins of ribosomal internal transcribed spacer diversity in apomictic Meloidogyne. Mol. Biol. Evol. 16, 157164.

Hwang J. S., Lee J. S., Goo T. W., Yun E. Y., Sohn H. Y., Kim H. R. and Kwon O. Y. (1999a) Molecular genetic relationships between Bombycidae and Saturniidae based on the mitochondria DNA encoding of large and small rRNA. Genet. Anal. Biomol. Eng. 15, 223-228.

Hwang J. S., Lee J. S., Goo T. W., Kang H. A., Yun E. Y., Sohn H. Y., Kim H. R. and Kwon O. Y. (1999b) The comparative Molecular study between Bombycidae and Saturniidae Based on mtDNA RFLP and Cytochrome oxidase I Gene sequences: Implication for Molecular Evolution. Z. Naturforsch. 54, 587594.

Jolly, M. S. (1985) Species differentiation in the genus Antheraea. Sericologia. 25, 84-94.

Kluge, A. G. and Farris, J. S. (1969) Quantitative phyletics and the evolution of anurans. Syst Zool. 18, 1-32.

Kumar, S., Tamura, K. and Nei, M. (2004) MEGA3: integrated software for molecular evolutionary genetics analysis and sequence alignment. Brief Bioinform. 5, 150-163.

Kundu, S. C., Ibotombi, N. and Bhagirath, T. (1991) Synaptonemal complex karyotype of an Indian silkworm, Antheraea roylei. Sericologica. 31, 543-547.

Li, A., Zhao, Q., Tang, S., Zhang, Z., Pan, S. and Shen, G. (2005) Molecular phylogeny of the domesticated silkworm, Bombyx mori, based on the sequences of mitochondrialcytochrome $\mathrm{b}$ genes. J. Genet. 84, 137-142.

Long, E. O. and David, B. (1980) Repeated genes in eukaryotes. Annual Ver. Biochem. 49, 727-764.

Mahendran, B., Acharya, C., Dash R., Ghosh, S. K. and Kundu, S. C. (2006) Repetitive DNA in tropical tasar silkworm Antheraea mylitta. Gene 370, 51-57.

Mahendran, B., Padhi, B. K., Ghosh, S. K. and Kundu, S. C. (2005) Genetic variation in ecoraces oftropical tasar silkworm, Antheraea mylitta D. using RFLP technique. Current Science 90, 100-103.

Marcilla, A., Bargues, M. D., Ramsey, J. M., Magallón-Gastélum, E., Salazar-Schettino, P. M., Abad-Franch, F., Dujardin, J. P., Schofield, C. J. and Mas-Coma, S. (2001) The ITS-2 of the nuclear rDNA as a molecular marker for populations, species, and phylogenetic relationships in Triatominae (Hemiptera: Reduviidae), vectors of Chagas disease. Mol. Phylogenet. Evol. 18, 136-142.

Marquez, L. M., Miller, D. J., MacKenzie, J. B. and Van Oppen, M. J. H. (2003) Pseudogenes contribute to the extreme diversity of nuclear ribosomal DNA in the hard coral Acropora. Mol. Biol. Evol. 20, 1077-1086.

Nagaraju, J. and Jolly, M. S. (1985). Interspecific hybrids of Antheraea roylei and A. pernyi - a cytogeentic reassessment. Theor. Appl. Genet. 72, 269-273.

Nagaraju, J., Kathirvel, M., Muthulakshmi, M., Subbiah, E. V. and Kumar, L. D. (2002) FISSR-PCR: a simple and sensitive assay for high throughput genotyping and genetic mapping. Mol. Cell. Probes. 16, 67-72.

Posada, D. and Crandall, K. A. (1998) MODELTEST: testing the model of DNA substitution. Bioinformatics 14, 817-818.

Prasad, M. D., Muthulakshmi, M., Madhu, M., Archak, S., Mita, 
K. and Nagaraju, J. (2005) Survey and analysis of microsatellites in the silkworm, Bombyx mori: frequency, distribution, mutations, marker potential and their conservation in heterologous species. Genetics. 169, 197-214.

Reddy, K. D., Abraham, E. G. and Nagaraju, J. (1999) Microsatellites of the silkworm, Bombyx mori: abundance, polymorphism and strain characterization. Genome. 42, 10571065.

Sambrook, J. and Russell, D. W. (2001) Molecular cloning: A laboratory manual 3rd ed., Cold Spring Harbor Laboratory Press, New York, USA.

Shimada, T., Kurimoto, Y. and Kobayashi, M. (1995) Phylogenetic relationship of silkmoths inferred from sequence data of the arylophorin gene. Mol. Phylogenet. Evol. 4, 223-234.

Sinha, A. K., Sinha, R. K., Goel, A. K., Sinha, B. R. R. Pd. and Thangavelu, K. (1994a) A review on the breeding and genetics aspect of tropical tasar silkworm, Antheraea mylitta. Proc. Conf. Cytology Genetics 4, 7-16.

Smith, G. P. (1976) Evolution of repeated DNA sequences by unequal crossover. Science 191, 528-535.

Strand, M., Prolla, T. A., Liskay, R. M. and Petes, T. D. (1993) Destabilization of tracts of simple repetitive DNA in yeast by mutations affecting DNA mismatch repair. Nature 365, 274276.

Swofford, D. L. (2003) PAUP*. Phylogenetic Analysis Using Parsimony (*and other methods). Sinauer Assoc, Sunderland, Massachusetts. Ver. 4.0b 10.

Tan, Y. D., Wan, C., Zhu, Y., Lu, C., Xiang, Z. and Deng, H. W. (2001) An amplified fragment length polymorphism map of the silkworm. Genetics 157, 1277-1284.

Therriault, T. W., Docker, M. F., Orlova, M. I., Heath, D. D. and MacIsaac, H. J. (2004) Molecular resolution of Dreissenidae (Mollusca: Bivalvia) including the first report of Mytilopsis leucophaetain the Black Sea basin. Mol. Phylogenet Evol. 30, 479-489.

Thompson, J. D., Higgins, D. G. and Gibson, T. J. (1994) CLUSTAL W: Improving the sensitivity of progressive multiple sequence alignment through sequence weighting, positions-specific gap penalties and weight matrix choice. Nucleic Acids Res. 22, 221-244.

Van Herwerden, L., Blair, D. and Agasuma, T. (1999) Intra-and interindividual variation in ITS1 of Paragonimus westermani (Trematoda: Digenea) and related species: implications for phylogenetic studies. Mol. Phylogenet. Evol. 12, 66-78.

Vidigal. T. H. D. A., Spatz, L., Kissinge,r J., Redondo, R. F., Pires, E. R., Simpson, A. J. G. and Carvalho, O. S. (2004) Analysis of the first and second internal transcribed spacer sequences of the ribosomal DNA in Biomphalaria tenagophila Complex (Mollusca: Planorbidae). Mem Inst Oswaldo Cruz, Rio de Janeiro. 99, 153-158.

Viguera, E., Canceill, D. and Ehrlich, S. D. (2001) Replication slippage involves DNA polymerase pausing and dissociation. EMBO J. 20, 2587-2595.

Yasukochi, Y. (1998) A dense genetic map of the silkworm, Bombyx mori, covering all chromosomes based on 1018 molecular markers. Genetics. 150, 1513-1525.

Zuker, M. (2003) Mfold web server for nucleic acid folding and hybridization prediction. Nucleic Acids Res. 31, 3406-3415. 